\title{
Fostering Child Development by Improving Care Quality: A Systematic Review of the Effectiveness of Structural Interventions and Caregiver Trainings in Institutional Care
}

TRAUMA, VIOLENCE, \& ABUSE 2017, Vol. I8(5) 544-56I (C) The Author(s) 2016 Reprints and permission: sagepub.com/journalsPermissions.nav DOI: $10.1177 / 1524838016641918$ journals.sagepub.com/home/tva (A) SAGE

\author{
Katharin Hermenau ',2, Katharina Goessmann', Niels Peter Rygaard ${ }^{3}$, \\ Markus A. Landolt ${ }^{2,4,5}$, and Tobias Hecker ${ }^{1,2,6}$
}

\begin{abstract}
Quality of child care has been shown to have a crucial impact on children's development and psychological adjustment, particularly for orphans with a history of maltreatment and trauma. However, adequate care for orphans is often impacted by unfavorable caregiver-child ratios and poorly trained, overburdened personnel, especially in institutional care in countries with limited resources and large numbers of orphans. This systematic review investigated the effects of structural interventions and caregiver trainings on child development in institutional environments. The 24 intervention studies included in this systematic review reported beneficial effects on the children's emotional, social, and cognitive development. Yet, few studies focused on effects of interventions on the child-caregiver relationship or the general institutional environment. Moreover, our review revealed that interventions aimed at improving institutional care settings have largely neglected violence and abuse prevention. Unfortunately, our findings are partially limited by constraints of study design and methodology. In sum, this systematic review sheds light on obstacles and possibilities for the improvement in institutional care. There must be greater efforts at preventing violence, abuse, and neglect of children living in institutional care. Therefore, we advocate for combining attachment theory-based models with maltreatment prevention approaches and then testing them using rigorous scientific standards. By using approaches grounded in the evidence, it could be possible to enable more children to grow up in supportive and nonviolent environments.
\end{abstract}

\section{Keywords}

institutional care, orphans, care quality, attachment, child maltreatment, prevention, interventions

\section{Introduction}

The quality of child care-especially in the early years of a child's life - has been shown to have a crucial impact on development and positive functioning later in life (R. Johnson, Browne, \& Hamilton-Giachritsis, 2006). With these findings in mind, good caregiving should include sensitive and consistent caregiver-child relationships (Hungerford \& Cox, 2006) as well as a stimulating, nonviolent, and educational environment (Field, 2002; National Institute of Child Health and Human Development Early Child Care Research Network, 2002). These factors are particularly important for children who have been maltreated or traumatized earlier during the course of their lives as is the case with many children living in institutional care. The purpose of the present study is to systematically review the current evidence on the effectiveness of structural interventions and caregiver trainings in institutional care in order to foster children's development through improving care quality and preventing maltreatment. We define structural interventions and caregiver trainings as interventions that aim to change the context of the institutions themselves as well as the ways in which caregivers interact with the children.

There has been a growing body of evidence pointing to the advantages of family-based care over the institutional placement of children in need (Dozier et al., 2014; Groza, McCreery Bunkers, \& Gamer, 2011; Nelson et al., 2007). The generation

\footnotetext{
'Department of Psychology, University of Konstanz, Konstanz, Germany

${ }^{2}$ vivo international, Konstanz, Germany

${ }^{3}$ FairstartGlobal, Denmark

${ }^{4}$ University Children's Hospital Zurich, Zurich, Switzerland

${ }^{5}$ Department of Child and Adolescent Health Psychology, Institute of Psychology, University of Zurich, Zurich, Switzerland

${ }^{6}$ Division of Psychopathology \& Clinical Intervention, Institute of Psychology, University of Zurich, Zurich, Switzerland
}

\section{Corresponding Author:}

Katharin Hermenau, Department of Psychology, University of Konstanz, Box 905, 78457 Konstanz, Germany.

Email: katharin.hermenau@uni-konstanz.de 
of this evidence has been followed by efforts to implement deinstitutionalization (Vashchenko, Easterbrooks, \& Miller, 2010). As a consequence, adopting children from institutions into families has become a widespread practice (McCall, 2013; Wolff \& Fesseha, 1998). However, in many countries, particularly in Sub-Saharan Africa and South Asia, the number of orphans has been constantly rising over the last several decades with estimated numbers of 56,000,000 and 40,800,000, respectively, in part as a consequence of the HIV/AIDS epidemic and armed conflicts (Maundeni \& Malinga-Musamba, 2013; United Nations Children's Emergency Fund, 2014). Due to poor economic conditions in countries with limited resources and the rising numbers of orphans, the capacities of family- or community-based care efforts have been overburdened and possibilities of foster care or adoption are very limited (Hermenau et al., 2011; Li et al., 2008). Thus, it is not surprising that in many parts of the world, child care institutions, such as orphanages and children's homes, still constitute the most frequently utilized form of providing care for children without parents (Neimetz, 2010; Rygaard, 2010).

However, institutions facing major difficulties due to unfavorable caregiver-child ratios and poorly trained, overburdened personnel often fail to provide care that meets the needs of orphaned or otherwise vulnerable children (D. E. Johnson, Dovbnya, Morozova, Richards, \& Bogdanova, 2014; McCall, 2013; Rather \& Margoob, 2006). Usually, the child care institutions are able to offer basic provisions of food and shelter, but they lack adequate means to offer sensitive, child-oriented care, possibly leading to the emotional and physical neglect of many children (Oliveira et al., 2012; Vashchenko et al., 2010). The lack of a loving and positive care environment is related to various negative outcomes in child development as well as physical and mental health (D. E. Johnson et al., 2010; R. Johnson et al., 2006; Rather \& Margoob, 2006; Van Ijzendoorn, Luijk, \& Juffer, 2008; Walakira, Ochen, Bukuluki, \& Alllan, 2014).

Furthermore, the aforementioned structural problems may also contribute to high levels of emotional and physical abuse in institutional care (Hermenau, Eggert, Landolt, \& Hecker, 2015; Hermenau, Hecker, Elbert, \& Ruf-Leuschner, 2014). For example, the reported worldwide rates of violence against children in institutional care were 6 times higher than those of children living in family-based foster care (Pinheiro, 2006). Untrained and undereducated caregivers, in particular, frequently used severe physical punishment to discipline the children (Hermenau, Kaltenbach, Mkinga, \& Hecker, 2015). Thus, in addition to trauma-related disorders due to the loss of a parent, other traumatic experiences and adversities during early childhood (Elbert et al., 2009; Ruf \& Schauer, 2012) as well as possible maltreatment in the family of origin, orphans and other children are burdened with further experiences of emotional and physical maltreatment in institutional care (Hermenau et al., 2011).

Following De Bellis and Zisk's (2014) framework of "developmental traumatology," child abuse and neglect are examples of a pathogenic relational environment. Children may develop a low-quality attachment bond or even lack an attachment relationship altogether in the absence of adequate care. Taken together with the experience of violence and abuse, this lack may impact the child's stress response system, and, in this way, the development and structure of the brain as well. These changes to neurodevelopment may lead to mental health problems, such as depression, posttraumatic stress disorder, and internalizing and externalizing problems (Connor, Doerfler, Volungis, Steingard, \& Melloni, 2003; Felitti et al., 1998; Hecker, Hermenau, Isele, \& Elbert, 2014). Further, individuals with a history of early institutional care showed more academic difficulties and deficits in social skills, such as maintaining trustful interpersonal relationships (Frank, Klass, Earls, \& Eisenberg, 1996; Merz, McCall, \& Wright, 2013). Beyond these impacts, child maltreatment has been related to epigenetic changes in the stress response axis (Hecker, Radtke, Hermenau, Papassotiropoulos, \& Elbert, 2016; McGowan et al., 2009).

Although both the number and the range of barriers to healthy development in institutional child care settings are undeniable (Dozier et al., 2014), child care institutions themselves possess great potential as a fruitful point of intervention, particularly in resource-poor countries (McCall, 2013; Vashchenko et al., 2010). This understanding has led to an increase in research efforts to find ways of protecting children from maltreatment and further harm during their time spent in institutional care (McCall, 2013; Rygaard, 2010). Interventions have generally aimed to improve caregiving and living conditions for affected children. Components of these interventions, however, are diverse, ranging from additional stimulation of the children to professional caregiver training, supervision systems, and changes in the structure of the institutions (e.g., family-like groups, primary caregiver assignment, etc.).

To our knowledge, there is, at this point, no general overview presenting the current state of research regarding the effectiveness of interventions on children's development in institutional environments. Prior meta-studies on the effects of interventions in institutional care focused solely on cognitive development (Bakermans-Kranenburg, van IJzendoorn, \& Juffer, 2008). In many low- and middle-income countries, general guidelines and quality control for institutional care are still lacking. To bridge this gap in research and to contribute to developing guidelines for improving care quality, this systematic review aims to examine structural interventions and caregiver trainings implemented around the globe. We focused on interventions that were conducted in institutional care settings, and which aimed to improve the children's development and living conditions by, for example, employing caregiver training or supervision, structural changes, or additional stimulation. A two-part hypothesis was proposed. Caregiver training, structural changes, and enriched caregiving environments (e.g., active stimulation) in child care institutions are expected to have beneficial effects on (1) children's emotional, social, and cognitive development 
and (2) the quality of care, the child-caregiver relationship and interactions as well as the overarching institutional environment.

\section{Method}

\section{Search Strategy and Study Selection}

In order to obtain qualified intervention studies for the analysis, we searched electronic literature databases (Medline, PubMed, PsycInfo, PSYNDEX, Web of Science, and Google Scholar) using the following search terms: "child care institution" (OR "orphanage," "children's home," "institutional care," "residential care," "group care"), AND “intervention" (OR "reorganization," “training," “changing," “improving," "modification," “stimulation"), AND “orphans" (OR "child," "infant”), AND "care quality" (OR "child care," "care condition," "caregiver"), AND "development" (or "behavioral changes," "attachment"). The searches were not limited by date. An overview of the selection process is presented in Figure 1. We supplemented our database review by searching the Infant Mental Health Journal by hand, as this journal has published many of the recent intervention studies in this area of research. To avoid the potential for publication bias, in our review, we searched for grey literature, that is, unpublished reports, master, and dissertation theses in the following databases using the same search terms described previously: DART-Europe, EThOS, OATD, DissOnline, proQuest, and clinicaltrials.org. Furthermore, we contacted the corresponding authors of all identified studies published or written within the previous 10 years and requested unpublished reports or articles in preparation or under review that may have qualified for inclusion in the present study. Our intensive search for grey literature and unpublished reports did not reveal further studies that fulfilled our inclusion criteria.

Following this search strategy, we identified the abstracts of 124 studies. These studies were published in English language, peer-reviewed journals between 1956 and July 2015. Following an a priori protocol, all studies were analyzed according to the following inclusion criteria: empirical studies with children as participants; studies with controlled and uncontrolled research designs, the presence of a control group composed of children living in the same institution or in comparable conditions; interventions with children aged 0-17 years living full time in child care institutions in any part of the world (studies assessing formerly institutionalized children or children in foster care were excluded); interventions implemented within institutions aiming to change the context of the institutions as well as the ways in which caregivers interacted with the children; and interventions that aimed to improve the children's development and living conditions by employing one or more intervention components (i.e., caregiver training or supervision, structural changes, or additional stimulation). Studies applying adoption or foster care measures as intervention approaches or exclusively including disabled children were excluded. Comparison conditions included "no intervention" or "pre-post comparisons." In terms of outcomes, studies were included which assessed factors of child development, children's health status, changes in the caregiving quality, or attachment. The actual form or timing of the outcome assessment was not a relevant excluding factor. In the case of several publications reporting the same studies, those articles were treated as one study. After the analysis of the abstracts, 98 studies were excluded due to unsuitability or absence of relevant aspects (see Figure 1 for reasoning). After full-text analysis, we excluded an additional five studies. In total, we identified 23 intervention studies within 21 articles fulfilling all inclusion criteria (see intervention characteristics for details). In an attempt to extend the sample, the reference lists of all selected articles were analyzed, and two international experts were consulted. This strategy yielded one further qualified study.

\section{Data Analysis}

According to Lakens (2013a), studies with nonmatched or randomized control groups perform independent observations, whereas designs with matched control groups or repeated measures are dependent observations. Intervention studies without control groups were analyzed using pre- to postintervention comparisons to assess their effects over time. In interventions with controlled designs, the main effects of intervention were analyzed. The consideration of Group $\times$ Time interaction effects was not possible in most studies due to methodological reasons. Where occasional interaction effects were reported, their effect sizes are reported in addition to the compared main effects of intervention.

Following Lakens' (2013a) suggestion, effect sizes will be expressed in Cohen's $d_{z}$ for dependent observations and in Cohen's $d_{s}$ for independent observations, respectively. Our metric for a small effect size was $d \geq .20$, for a medium effect $d \geq .50$, and for a large effect $d \geq .80$ (Cohen, 1992). Effect sizes of studies providing different effect size parameters, such as Cohen's $d_{a v}$, were converted into Cohen's $d_{z}$ or Cohen's $d_{s}$. The effect sizes for studies providing values of $t$-tests or $F$ tests with $1 d f$ and group sizes were calculated using Lakens' (2013b) calculation sheet for effect sizes. For the following seven studies, effect size data were retrieved from a previous meta-analysis (Bakermans-Kranenburg et al., 2008) because data for calculation were not available and contacting study authors to receive missing data was not successful: Brossard and Decarie (1971); Casler (1965a); Gavrin and Sacks (1963); Hunt, Mohandessi, Ghodssi, and Akiyama (1976); Sayegh and Dennis (1965); Sparling, Dragomir, Ramey, and Florescu (2005). Some studies separately reported results for quasicross-sectional and true longitudinal samples (i.e., the same participants assessed at both time points). In these cases, only the results of true longitudinal samples were analyzed due to their "displaying true intraindividual change" (McCall et al., 2010). When more than one postmeasurement was performed, the latest time point for which data were available was taken into account (excluding the follow-up assessment of the study by Hakimi-Manesh, Mojdehi, and Tashakkori, 1984 for which 


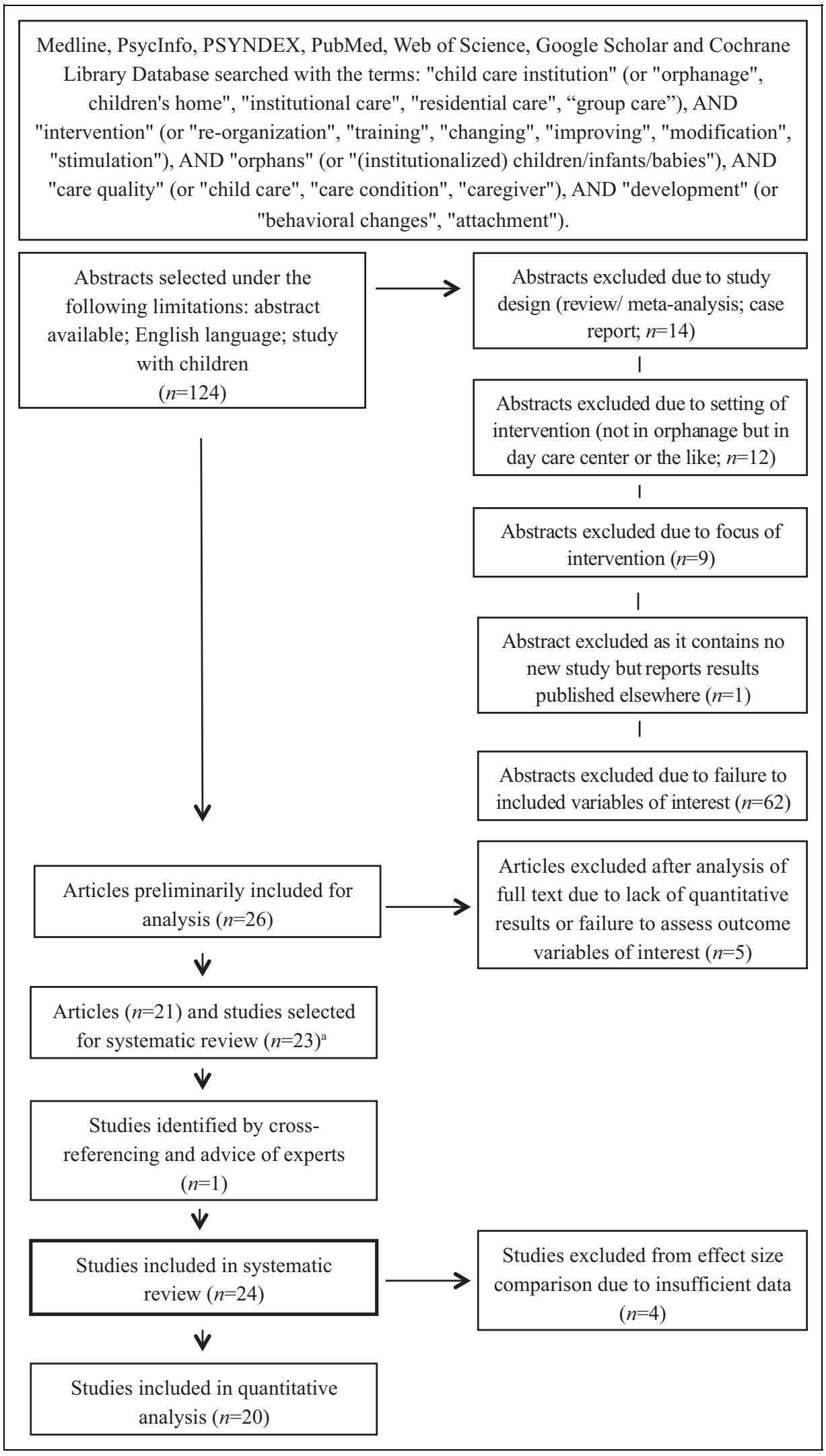

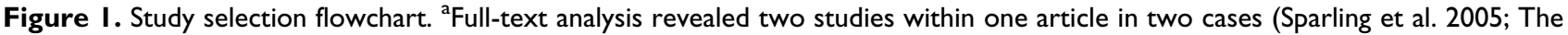
St. Petersburg-USA Orphanage Research Team 2008), thus we included 24 studies within 22 articles at this point of the study search. 
data were not calculable). We abstained from calculating pooled effect sizes or other meta-analytic measures because the validity of the findings was limited as a result of the poor study design and methods of the included studies (see below). Furthermore, the heterogeneity across studies was very large.

The outcome variables were grouped into two categories: (1) development and health, which included all aspects of children's cognitive, mental, psychomotor, verbal, behavioral, social, and physical development as well as mental and physical health variables and (2) caregiving or institutional quality and attachment. The latter covers all outcome variables related to the environment of the institution and caregiver-child interactions and attachment styles. For each category, outcomes of studies with dependent and independent designs were examined separately. Four studies (Casler, 1965b; Espié et al., 2011; Wolff, Dawit, \& Zere, 1995; Wright, Lamsal, Ksetree, Sharma, \& Jaffe, 2014) only provided qualitative descriptions of results or failed to supply relevant data to calculate effect sizes (e.g., missing standard deviations).

\section{Results}

The search strategy identified 24 relevant intervention studies. Effect size calculation was possible for 20 of the 24 included studies. Studies without control groups and studies with matched control groups were considered as dependent designs $(k=9)$. Studies with nonmatched or randomized control studies were regarded as independent $(k=11)$.

\section{Study Characteristics}

The 24 included studies examined interventions that were conducted in child care institutions in 15 different countries on 5 continents (see Table 1). Following the World Bank's definition (2014), 29\% of the studies were conducted in low or lower middle-income countries, $29 \%$ in upper middleincome countries, and $42 \%$ in high-income countries. Most authors implemented their intervention in one institution; only three studies compared several institutions within the same study. Interventions took place in state-run and private institutions. The included studies incorporated a total of 1,253 children. The age of the children ranged from below 4 weeks (Espié et al., 2011; Hunt, Mohandessi, Ghodssi, \& Akiyama, 1976; Kim, Shin, \& White-Traut, 2003) to 16 years (Hermenau, Kaltenbach, et al., 2015; Hermenau et al., 2011), with most children being infants or toddlers (64\%). In most cases, postassessments occurred at intervals between a few days and up to 3 years after completion of the intervention, with an average interval of 10 months. Conditions in many child care institutions were described as deficient before interventions began. Unfavorable child-caregiver ratios (Hakimi-Manesh, Mojdehi, \& Tashakkori, 1984; Kim et al., 2003; Lecannelier, Silva, Hoffmann, Melo, \& Morales, 2014), high levels of depressive symptoms and work overload among caregivers (Hakimi-Manesh et al., 1984; The St. Petersburg-USA Orphanage Research Team, 2008), and unsecure political conditions in the country (Wolff et al., 1995) were some examples cited by researchers.

\section{Intervention Characteristics}

In 15 studies, intervention components focused on training and building the capacity of caregivers, and 10 studies included structural changes in the child care institutions. Only seven of the included studies were theory based (see Table 2 for details). Five studies based their intervention approach on attachment theory (Lecannelier et al., 2014; McCall et al., 2010; Smyke, Dumitrescu, \& Zeanah, 2002; The St. Petersburg-USA Orphanage Research Team, 2008, Studies 1 and 2). Hermenau et al. (2011) and Hermenau, Kaltenbach, Mkinga, and Hecker (2015) utilized the consequences of repeated exposure to childhood adversities on children's mental health as a theoretical basis for their intervention. Only three studies applied a manualized intervention (Hermenau, Kaltenbach, et al., 2015; Lecannelier et al., 2014; McCall et al., 2010). Nine of the included studies used narrow intervention approaches providing supplementary stimulation for the children or structural changes in the institutions (stimulation or structural changes approach). Most of these interventions were provided by external specialists and did not involve the caregiving staff of the target institution. The stimulation interventions lasted 5.3 weeks on average. Each of these studies had experimental and control groups, but only two used a randomized controlled design (HakimiManesh et al., 1984; Kim et al., 2003). In the nine studies using a stimulation or structural changes approach, the total number of children examined was 250 and the average number of children per study was 28 . The other 15 studies provided broader intervention approaches focused on caregiver training or supervision and additional structural changes (training approach), with an average duration of approximately 10 months. The most complex study carried out two different interventions simultaneously (caregiver training plus structural changes, $\mathrm{T}+\mathrm{Sc}$, or caregiver training only, $\mathrm{TO}$ ) in two institutions and compared each one of them to a third institution receiving no intervention (The St. Petersburg-USA Orphanage Research Team, 2008). They also examined groups of children with and without disabilities; however, we considered only the typically developing children included in the study for the purposes of our review. Further, we considered each intervention approach as a single study (Study 1: T + Sc $[n=108]$ and Study 2: TO $[n=110]$ ). Sparling et al. (2005) also reported two intervention studies within one publication which are presented separately here. There were 1,003 children examined in training approach interventions, which made up $80 \%$ of the total sample of all included studies, with an average sample of 67.

\section{Outcome Measures}

The studies reported effects on more than 20 different outcome measures regarding the children as well as the institutional 


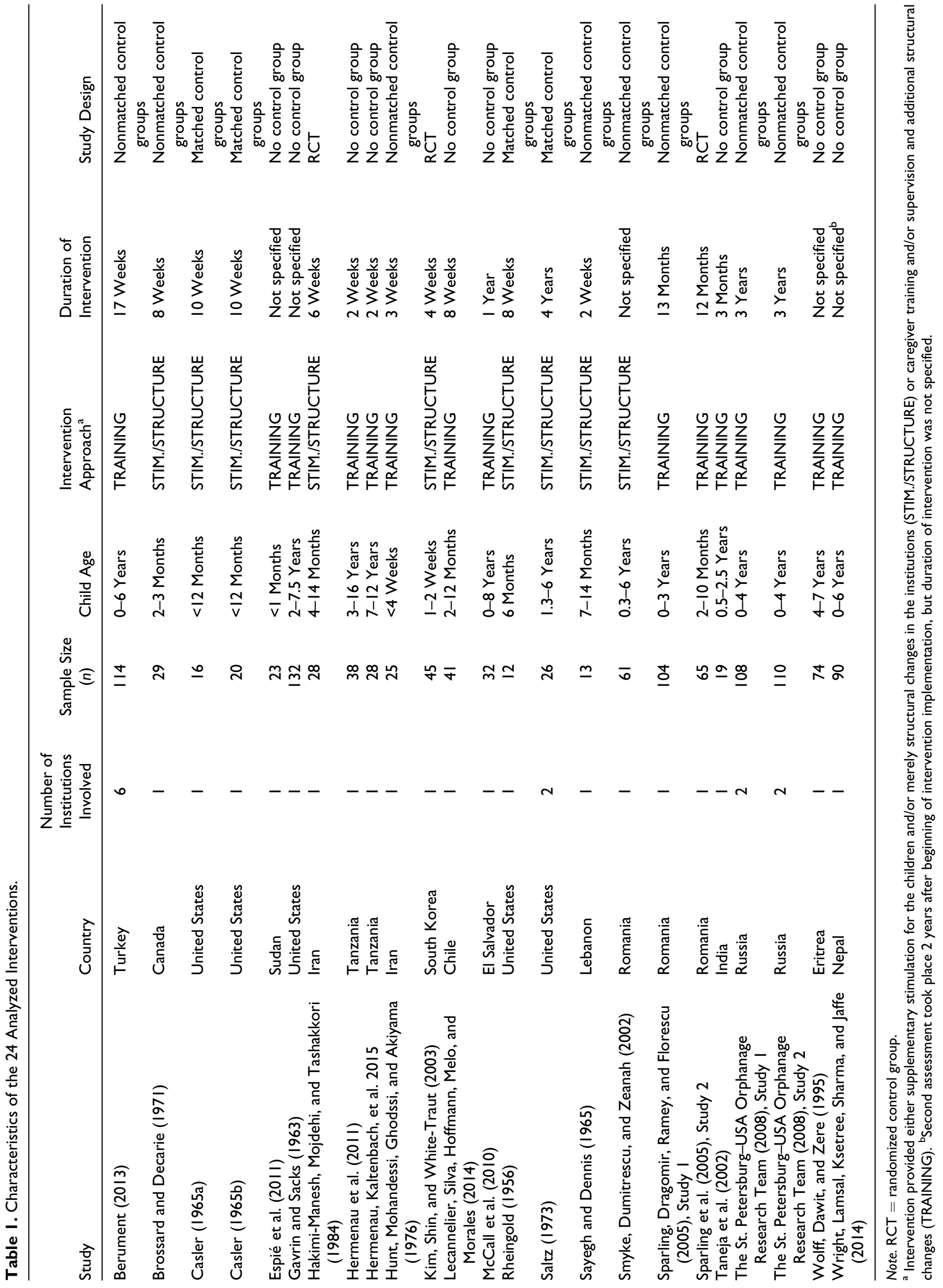


Table 2. Main Results of the 24 Analyzed Interventions.

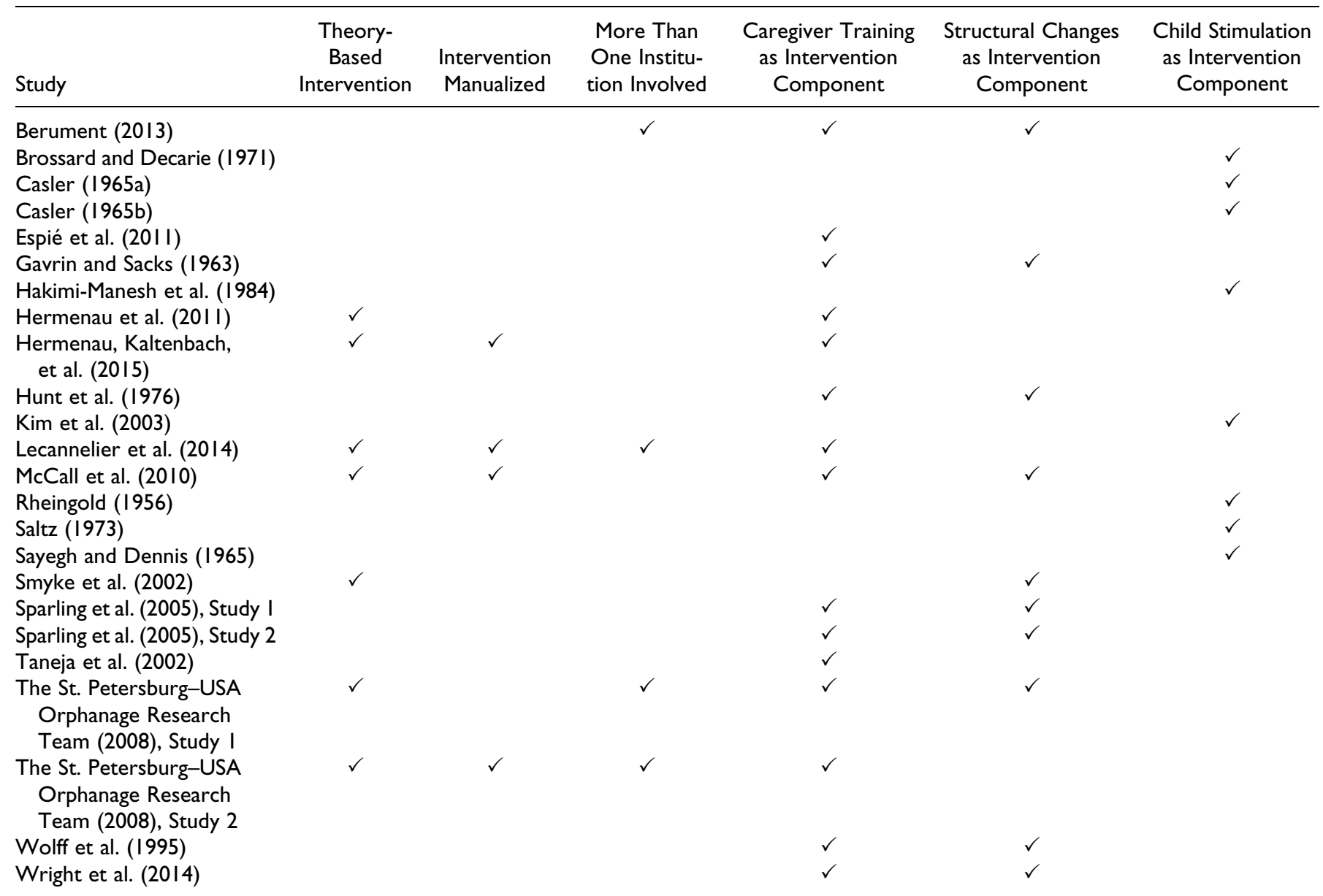

Note. $\checkmark=$ yes/true.

environment. They used more than 15 different assessment instruments including several intelligence tests, general development scales, language ability measures, physical development measures, mental health questionnaires, behavior records as well as attachment and interaction quality measures. The most frequently applied instruments were the Cattell Infant Intelligence Scale (Cattell, 1940) and the Denver II (Frankenburg \& Dodds, 1990), both measuring intelligence and developmental quotients. For details of the applied instruments see Tables 3 and 4 .

\section{Intervention Effects on Development and Health}

Dependent designs. Nine intervention studies with dependent designs reported intervention effects on the children's developmental and/or health status. The majority of studies focused on development, but the observed aspects varied greatly. Seven studies focused on mental and psychomotor development variables (see Table 3). Three of them (Lecannelier et al., 2014; Rheingold, 1956; Taneja et al., 2002) also applied social behavior measures. Hermenau et al. (2011) and Hermenau,
Kaltenbach, et al. (2015) reported outcomes regarding different mental health variables (see Table 3 ).

Effect sizes (Cohen's $d_{z}$ ) of children's development and health varied greatly (range: $0.30-2.54$ ), indicating positive changes in children's development. Three studies had very large effects with $d_{z}=1.35$ ( $p<.01$; McCall et al., 2010), $d_{z}$ $=1.67$ ( $p<.0001$; Taneja et al., 2002), and $d_{z}=2.54(p<.001$; Rheingold, 1956). While Rheingold (1956) conducted a stimulation study with a very large effect, the other stimulation study by Saltz $(1973)$ showed a moderate effect $\left(d_{z}=0.61, p<.01\right)$ on developmental and health factors. The remaining seven dependent studies provided complex training approaches.

Independent designs. Ten of the 11 studies with independent designs reported intervention effects on children's development or health (see Table 4), one of them for both subcategories (Kim et al., 2003; physical development and physical health). Again, most researchers focused on developmental characteristics, using general and mental development as observed outcome variables in $73 \%$ of the studies.

Effect sizes (Cohen's $d_{s}$ ) of children's development and health varied greatly (range: 0.12-2.06). Most studies showed 


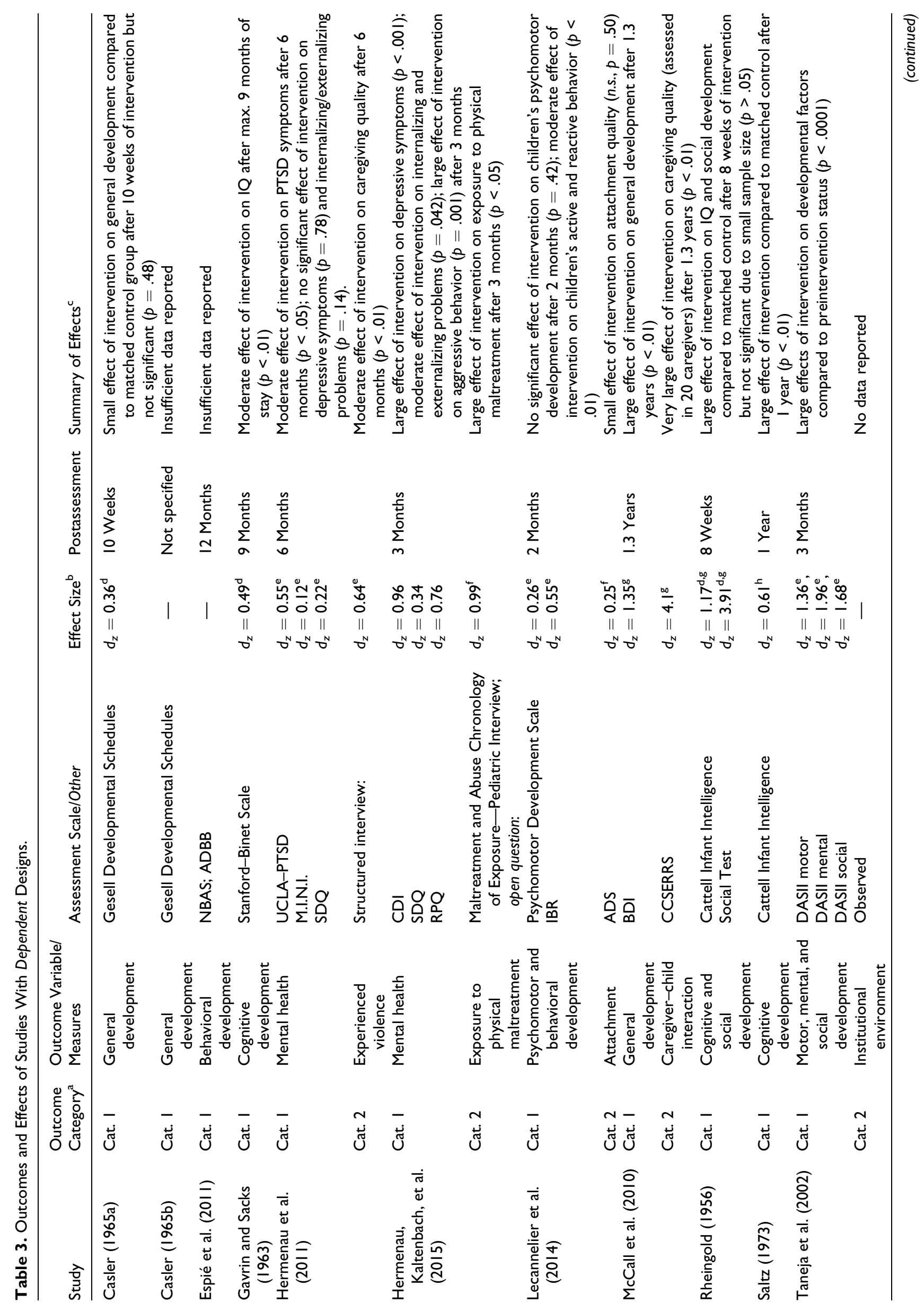




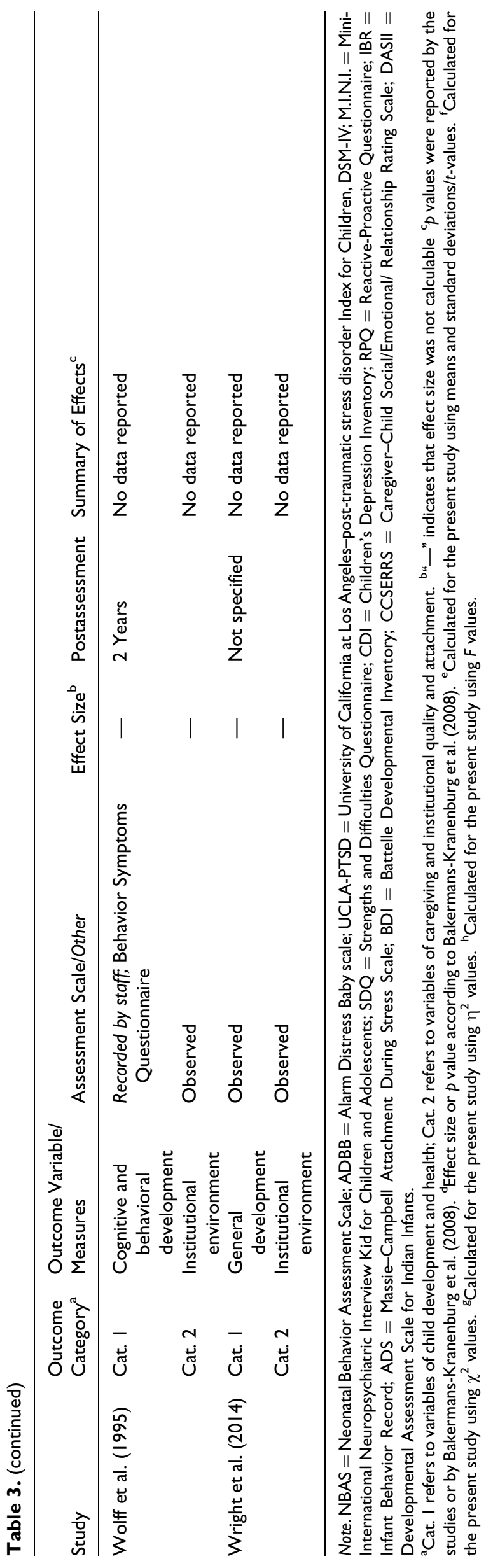




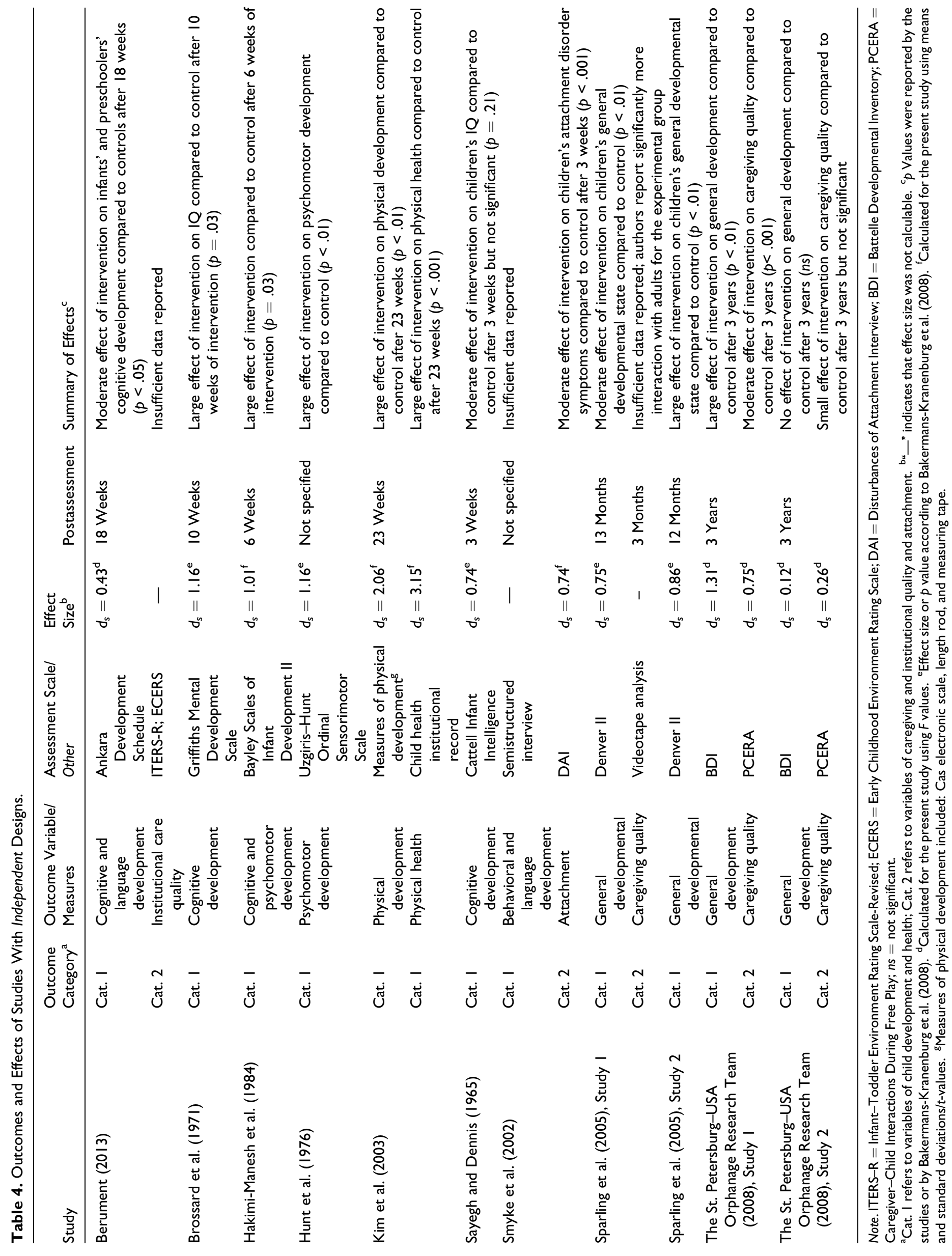


moderate to large effect sizes. One study reported a very large effect size of $d_{s}=3.15$ ( $p<.001$; Kim et al., 2003; physical health). Training interventions (range: 0.12-1.31) reported small to large effects, and stimulation/structural interventions (range: $0.74-2.06$ ) displayed moderate to large effects indicating an overall advantage of the intervention groups compared to control groups. Berument (2013) and Kim, Shin, and White-Traut (2003) provided Time $\times$ Group interaction effects on children's development ranging from $\eta_{p}{ }^{2}<0.01$ to $\eta_{p}{ }^{2}=$ 0.13 . This indicates very small to moderate interaction effects. Smyke, Dumitrescu, and Zeanah (2002) also measured developmental and behavioral variables using a semistructured interview, but effect sizes were not calculable due to the insufficient report of data.

\section{Intervention Effects on Caregiving or Institutional Quality and Attachment}

Dependent designs. Four of the nine studies with dependent designs examined changes in the quality of caregiving and the institutional environment or attachment variables, all considering different outcomes and assessment instruments (see Table 3). Because of this variety, the range of effects was very large (range: 0.25-4.10): Lecannelier, Silva, Hoffmann, Melo, and Morales (2014) reported a small but not significant effect of a caregiver training on the children's attachment styles $\left(d_{z}=\right.$ $0.25, p=.50$ ). Hermenau et al. (2011) measured the effect of a caregiver training intervention on the violence exposure of children living in a child care institution, reporting a moderate effect $\left(d_{z}=0.64, p<.01\right)$. Hermenau, Kaltenbach, et al. (2015) assessed the impact of caregiver training on the occurrence of physical maltreatment of children in an institution with a large effect $\left(d_{z}=0.99, p<.05\right)$. McCall et al. (2010) reported a very large effect $\left(d_{z}=4.10, p<.01\right)$ of a training intervention with additional structural changes on institutional quality. A fifth study with a dependent design (Taneja et al., 2002) also observed institutional environment but failed to provide calculable data. However, authors described notable changes in the caregivers' behavior.

Independent designs. Only 5 of the 11 studies with independent designs focused on outcomes of institutional and caregiving quality or attachment variables, each using different instruments (Berument, 2013; The St. Petersburg-USA Orphanage Research Team, 2008, Studies 1 and 2; Smyke et al., 2002; Sparling, Dragomir, Ramey, \& Florescu, 2005, Study 1). None of them used a randomized controlled design. Moreover, only three of the studies provided sufficient information to calculate main effects of the intervention (see Table 4). Two of them presented almost commensurate effect sizes: The St. Petersburg-USA Orphanage Research Team (2008) Study 1 reported a moderate effect on child-caregiver interaction quality in the intervention group that had received a comprehensive training intervention plus structural changes in contrast to the control group with no intervention $\left(d_{s}=0.75, p<.001\right)$. Also, Smyke et al. (2002) found a moderate effect on attachment in the intervention group in which the child-caregiver ratio has been improved compared to the control group $\left(d_{s}=0.74, p<.001\right)$. In contrast, the second study, conducting a training-only approach, by The St. Petersburg-USA Orphanage Research Team (2008) showed only a small effect on child-caregiver interaction quality when compared to the control group that did not reach statistical significance $\left(d_{s}=0.26\right.$, not significant). Berument (2013) did not provide data for main effects but reported a large Time $\times$ Group interaction effect $\left(\eta_{p}{ }^{2}=0.83, p<.001\right)$ on care quality for both younger and older children together. The fifth controlled study observing variables of environmental quality or attachment (Sparling et al., 2005; Study 1) did not provide numeric data for any effect size calculation but described significantly more interaction with adults for the intervention group in videotaped caregiver-child interactions.

\section{Discussion}

\section{Summary of Evidence}

The present review provides insight into the current state of research on peer-reviewed structural interventions and caregiver trainings for child care institution improvement by systematically examining and comparing a wide range of varying interventions conducted over the last 65 years. Our systematic literature search revealed only 24 intervention studies involving 1,253 children. This underlines that the knowledge regarding interventions that address the structure of institutions and the relation between caregiver and children in institutional care is limited thus far, and further research is needed to provide practical guidelines on how to improve institutional care in order to foster children's development.

Nevertheless, our findings are in concordance with our hypothesis that caregiver trainings, structural changes, and enriched caregiving environments in child care institutions have beneficial effects on the child's emotional, social, and cognitive development. Nine intervention studies with dependent designs reported moderate to large effects and 10 with independent designs reported small to large effects on the children's developmental and health status. Very few studies (four with dependent design and five with independent design) focused on the hypothesis that caregiver training, structural changes, and an enriched caregiving environment in child care institutions would have beneficial effects on the quality of care, the child-caregiver relationship, and the general institutional environment. These studies supported our hypothesis showing small to moderate effect sizes. However, more studies focusing on improvement in the general caregiving environment and particularly on the caregiver-child relationship (i.e., attachment and bonding) and prevention of maltreatment are needed.

The intervention approaches were only theory based in less than one third (29\%) of the studies included, and only three studies applied a manualized interventions approach. The major theoretical orientation was attachment theory. As a consequence of parental loss, and the many and changing caregivers, institutionalized children often lack a secure and 
stable attachment to a caregiver (McCall, 2013). The attachment theory implies that long-term adverse effects might be avoided if caregiving standards in the institution were improved because better caregiving should produce more organized and secure attachments as well as better stress regulation (McCall, 2013).

Overall, our findings indicate the need for increasing efforts to improve quality of care in institutional care. The predominant finding of mainly positive effects regarding a wide range of factors demonstrates that structural interventions and caregiver trainings have the potential to contribute effectively to an improvement in children's living conditions in institutional care and, subsequently, on their development. The effect sizes of developmental factors for independent and dependent designs are very similar to the combined effect of adoption on IQ ( $d=$ 1.17) reported in a study by Van Ijzendoorn, Juffer, and Klein Poelhuis (2005). Our results are also in accordance with previous findings from research on institutional interventions which point out the generally high improvement potentials of child care institutions as well as the children's abilities to overcome previous delays if their living environment is enriched (cf. Bakermans-Kranenburg et al., 2008).

The differing approaches found only partly reflect the time period in which the interventions were conducted. Although the majority of studies with additional stimulation as intervention date back to the 1950s to 1970 s, also today many child care institutions in resource-poor countries do not offer small children enough stimulation that would be necessary for a healthy development. As such, these studies can serve as a helpful starting place for institutions that are attempting to enrich the environments of the children under their care. Nevertheless, the tendency of more recent intervention studies to apply several intervention contents simultaneously can generally be considered commendable in terms of promoting adequate child care. While caregiver trainings show rather small and unspecific effects, their impact is considered stable and sustainable (cf. The St. Petersburg-USA Orphanage Research Team, 2008). Particularly, caregiver training (attachment orientated) and structural changes in institutions ("family-like environment") imply that caregivers spent more quality time with the children, thus improving the child-caregiver relationship and providing additional stimulation for the children (Hermenau et al., 2011; Rygaard, 2010).

\section{Limitations of the Included Studies}

The body of evidence in this systematic review comes from 24 studies involving 1,253 children from 15 countries. However, the informative value and the validity of the results of this review remain limited. First, the results of the database search revealed only a small number of studies fulfilling our inclusion criteria. Second, nine of the studies included had no control group. The validity of effects of uncontrolled studies is limited due to the fact that improvements observed in outcome variables are not necessarily attributable to the intervention itself. The other 15 studies had controlled designs, yet 7 of them only used quasiexperimental designs with intervention groups and nonmatched control groups. Four studies compared intervention groups toas far as possible - matched control groups from a different institution or within the same institution, and only three studies were randomized controlled trials (see Table 5 for details). Studies with control groups, however, sometimes lacked a longitudinal design. Thus, group comparisons were limited to intervention main effects and did not allow the calculation of Time $\times$ Treatment interactions. The lack of control groups in more than a third of the studies, as well as the significant attrition rates depleting participant sample sizes (average decrease 32\%), illustrate the obstacles involved in the implementation of intervention studies adhering to rigorous scientific standards in this research area. Due to a lack of longitudinal designs or a failure to present Time $\times$ Interaction effects, the internal validity of the controlled studies is also limited. However, researchers have to react to the reality of care institutions, such as heavy caregiver turnover and children moving in and out of the system. While this can pose a threat to internal validity, it can also increase external validity and, thus, the feasibility of practical implementation outside research settings. All but nine studies had a very small sample size $(n<50)$, and only one of them (Kim et al., 2003) reported power calculations. Many studies were also poor in their reporting or lacking in quality with respect to methods sequence generation and allocation concealment, incomplete outcome data, reliance on self-reported outcomes, and poor reliability and validity of instruments used to measure outcomes (see Table 5). Therefore, internal validity of the studies is unclear and likely to be poor. However, the studies by The St. Petersburg-USA Orphanage Research Team (2008) and Berument (2013), while using nonmatched control groups, are notable exceptions and present relatively reliable results.

\section{Limitations of Present Systematic Review}

Due to the inclusion of studies with different designs, it was necessary to calculate two different effect sizes: Cohen's $d_{z}$ for dependent and Cohen's $d_{s}$ for independent designs. As a consequence of this classification, sound methodological designs (i.e., randomized or matched controls) have been grouped with less rigorous designs (i.e., nonmatched controls or uncontrolled studies). Calculation of the preferable Cohen's $d_{r m}$, which additionally controls for the correlation of the two measurement points and which allows comparisons across within- and between-subject designs (Lakens, 2013a), was not possible due to a lack of reporting correlation values in most studies. Hardly any of the included studies provided effect sizes for their measured results. Thus, additional calculation and using information provided by a previous meta-analysis (BakermansKranenburg et al., 2008) was necessary. Yet, this may be problematic, as the numbers retrieved from another study could be erroneous and this may have impacted our findings. Four studies (Casler, 1965b; Espié et al.,2011; Wolff et al., 1995; Wright et al., 2014) failed to provide any calculable data, and information from other sources was not available. Furthermore, our literature search was limited to studies published in the 
Table 5. Risk of Bias.

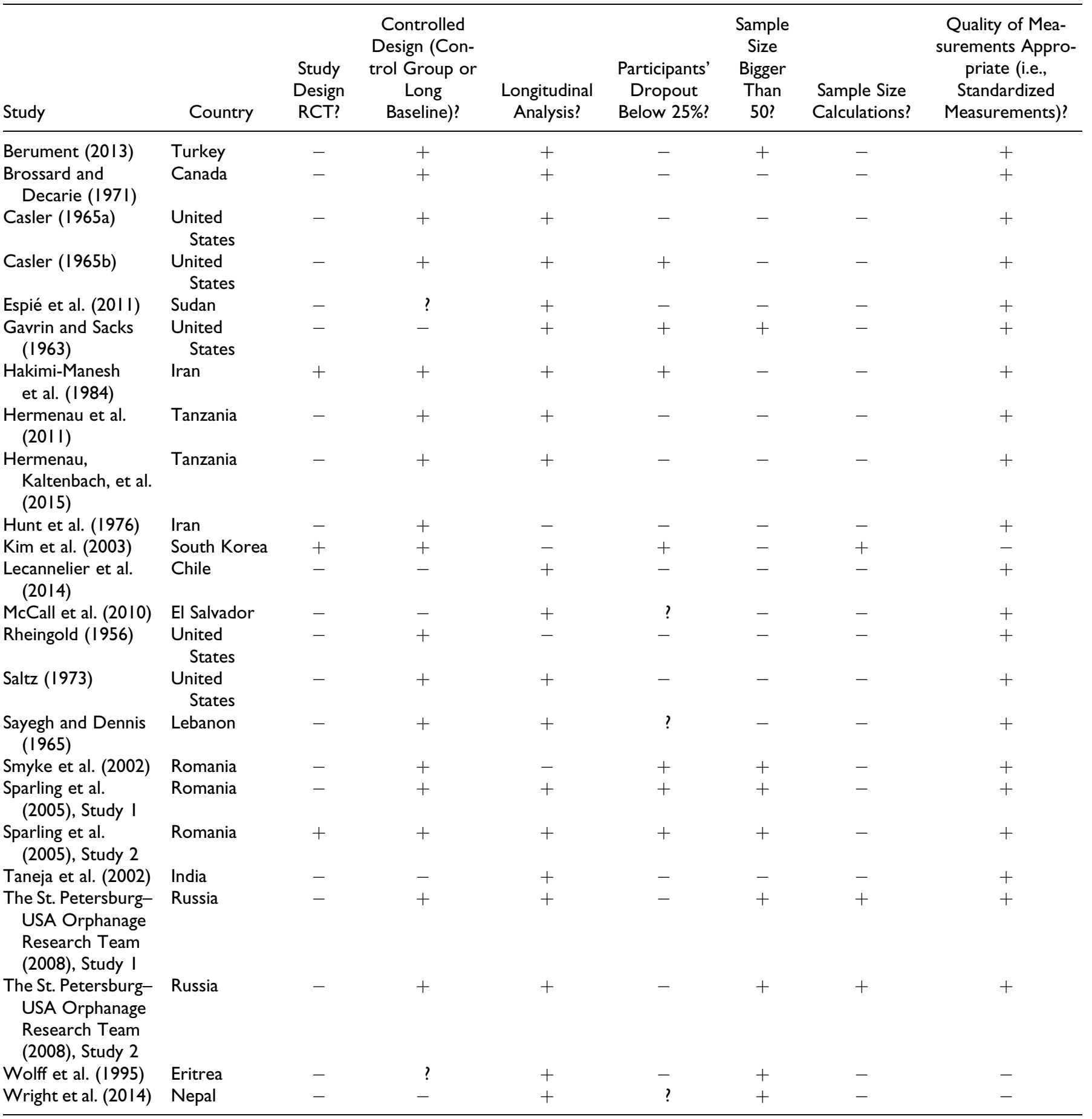

$+=$ yes/true

$-=$ no/not true.

? = questionable/unclear.

English language. Although many studies that were conducted in non-English-speaking countries were published in the English language, there may be relevant studies published in other languages. As a result, we cannot completely rule out that this potential selection bias may have impacted our results in an unknown way. The studies were conducted in 15 countries worldwide and across the span of several decades indicating heterogonous environmental conditions and cultural influences. Furthermore, the studies used different interventions and various outcome measures. This potentially limits the internal validity of our findings, as additional factors may have not been controlled. However, the external validity and generalizability 
of our findings may be higher due to the heterogeneous and naturalistic set of studies.

\section{Future Research Directions}

The small number of studies that our systematic literature search revealed clearly indicates that the research question of how to improve institutional care to foster children's development has been mainly neglected so far. Our findings underline the urgent need to address this research question using rigorous scientific standards, as the number of children who grow up in institutional care is rapidly increasing, particularly in resource-poor countries.

As different as the institutions were from one another, the intervention approaches were equally diverse. Our findings have shown that less than one third of the intervention approaches were theory based, and only three studies applied manualized interventions. Therefore, we advocate for developing theory-based and manualized training concepts for institutional caregivers that may be based on attachment and that can be tested using rigorous scientific standards. Such training concepts should be able to sustainably improve the life of children in institutional care and be applicable across different institutional settings worldwide. One promising approach that is theory based and manualized is FairstartGlobal (www.fairstartglobal.com). It is a curriculum rooted in attachment theory that promotes appropriate caregiver-child interactions and relationships. Its unique benefits include free availability on the Internet, implementation flexibility, administrator and staff involvement in creating its implementation, translation into 26 languages, and current implementation in numerous countries around the globe (McCall, Groark, \& Rygaard, 2014; Rygaard, 2010). Yet, its effectiveness still needs to be evaluated.

Abusive discipline measures are still very prevalent in many countries around the world (Stoltenborgh, BakermansKranenburg, Alink, \& van Ijzendoorn, 2012; Stoltenborgh, Bakermans-Kranenburg, van Ijzendoorn, \& Alink, 2013; Straus, 2010). In resource-poor countries in regions such as Sub-Saharan Africa and South Asia, caregivers are often poorly educated and overstrained. This paucity, coupled with the fact that children living in institutional care are more likely to show behavioral and emotional problems due to early experiences of maltreatment, leaves these children at an elevated risk of experiencing further maltreatment in institutional care (Hermenau et al., 2014). Although the negative impact of maltreatment on the children's development is undeniable (Gershoff, 2002; Hecker, Hermenau, Salmen, Teicher, \& Elbert, 2016), only two studies included in this review focused on the prevention of violence and abuse in institutional care (Hermenau, Kaltenbach, et al., 2015; Hermenau et al., 2011). The prevention of physical and emotional abuse in institutional care has otherwise been largely neglected thus far. In contrast to this, the major child maltreatment prevention strategy, developed by the Center for Disease Control and Prevention, the Safe, Stable, Nurturing Relationships (SSNR) framework is advocating for (1) measuring the impact of child maltreatment systematically, (2) creating and evaluating new approaches to
Table 6. Critical Findings.

(I) Structural interventions and caregiver trainings contribute to an improvement in children's living conditions in institutional care.

(2) Training of caregivers and structural changes have beneficial effects on the children's development.

(3) The prevention of physical and emotional abuse in institutional care has widely been neglected.

(4) More efforts are needed to focus on the improvement of general caregiving environment, caregiver-child relationship, and maltreatment prevention.

Table 7. Implications for Practice, Policy, and Research.

(I) Broad, theory-based approaches are needed and should be tested using rigorous scientific standards.

(2) Responsive nonviolent caregiver-child interactions are crucial to children's physical and behavioral development.

(3) Beyond improving caregiver-child attachment, caregiver trainings should also focus on prevention of violence and abuse in institutional care.

(4) Improving the quality of care may be more important than the type of care (e.g., institutional care vs. foster care).

prevention, (3) applying and adapting evidence-based practices, and (4) building community readiness. In line with the SSNR framework and the fact that abusive discipline measures frequently occur in institutional care settings and that they can add to the psychological burden of prior parental loss and possible adverse experiences in the family of origin (Hermenau et al., 2014), there must be greater efforts at preventing violence against and the abuse and neglect of children living in institutional care (Hermenau, Kaltenbach, et al., 2015).

\section{Recommendations for Institutional Care Policies}

Many of the intervention approaches included in the studies of the present review have some important components in common: They all aim at improving the caregiver-child relationship (attachment and bonding), enriching the caregiving environment through additional stimulation and quality time, and at least some focus on preventing maltreatment and further harm (Hermenau, Kaltenbach, et al., 2015; McCall \& Groark, 2015; Rygaard, 2010). When designing interventions or improving care facilities, governmental officials, institutional directors, and caregivers should focus on these core elements. Researchers can support practitioners in testing these core elements in rigorous research designs that provide clear conclusions and practical implications.

From our findings and the examples of successful attempts to improve care quality and to prevent maltreatment in institutional care, we can, therefore, conclude two important practical implications: (a) although basic nutrition, sanitation, safety, and medical care are essential, responsive nonviolent caregiverchild interactions are also crucial to children's physical and behavioral development; and (b) improving quality of care may be more important than the type of care (see Tables 6 and 7). 


\section{Conclusions}

In sum, the results of this review suggest that different interventions seem to have a positive impact on the children's development as well as the environmental factors that may also positively influence the children's development (e.g., childcaregiver attachment). Therefore, we advocate for testing theory-based and manualized intervention approaches by using rigorous scientific standards. Training caregivers and involving them in structural changes enhance the likelihood for sustainable effects. Moreover, our review revealed that interventions aimed at improving institutional care settings have largely neglected the prevention of violence and abuse. Thus, programs mainly based on attachment theory need to be expanded to be able to protect children from further maltreatment and harm in institutional settings. The sustainable implementation of evidence-based prevention programs in child care institutions will enable more children around the globe to grow up in supportive and nonviolent environments, thereby helping them to develop in a healthy manner.

\section{Acknowledgments}

We are very grateful to Thomas Elbert and Katharina Zepf for their support in this study. We thank Christine Groark and Adrian Rus for reviewing the list of studies included in this systematic review and Danie Meyer-Parlapanis and Justin Preston who critically reviewed the article.

\section{Declaration of Conflicting Interests}

The author(s) declared no potential conflicts of interest with respect to the research, authorship, and/or publication of this article.

\section{Funding}

The author(s) disclosed receipt of the following financial support for the research, authorship, and/or publication of this article: This research was supported by the Deutsche Forschungsgemeinschaft (DFG).

\section{References}

References marked with an asterisk indicate studies included in the systematic review.

Bakermans-Kranenburg, M. J., van IJzendoorn, M. H., \& Juffer, F. (2008). Earlier is better: A meta-analysis of 70 years of intervention improving cognitive development in institutionalized children. Monographs of the Society for Research of Child Development, 73, 279-293. doi:10.1111/j.1540-5834.2008. 00498.x

*Berument, S. K. (2013). Einvironmental enrichment and caregiver training to support the development of birth to 6-years-olds in Turkish orphanages. Infant Mental Health Journal, 34, 189-201. doi:10.1002/imhj.21380

*Brossard, M., \& Decarie, T. G. (1971). The effects of three kinds of perceptual-social stimulation on the development of institutionalized infants. Early Child Development and Care, 1, 111-130. doi: $10.1080 / 0300443710010109$
*Casler, L. (1965a). The effects of extra tactile stimulation on a group of institutionalized infants. Genetic Psychology Monographs, 71, 137-175.

*Casler, L. (1965b). The effects of supplementary verbal stimulation on a group of instituionalized infants. Journal of Child Psychology and Psychiatry, 6, 19-27.

Cattell, P. (1940). The measurement of intelligence of infants and young children. San Antonio, TX: Psychological Corporation.

Cohen, J. (1992). A power primer. Psychological Bulletin, 112, 155-159. doi:10.1037/0033-2909.112.1.155

Connor, D. F., Doerfler, L. A., Volungis, A. M., Steingard, R. J., \& Melloni, R. H. (2003). Aggressive beheavior in abused children. Annals of the New York Academy of Sciences, 1008, 79-90. doi:10. 1196/annals.1301.009

De Bellis, M. D., \& Zisk, A. (2014). The biological effects of childhood trauma. Child and Adolescent Psychiatrc Clinics of North America, 23, 185-222. doi:10.1016/j.chc.2014.01.002

Dozier, M., Kaufman, J., Kobak, R., O’Connor, T. G., Sagi-Schwartz, A., \& Scott, S., ... Zeanah, C. H. (2014). Consensus statement on group care for children and adolescents: A statement of policy of the American Orthopsychiatric Association. American Journal of Orthopsychiatry, 84, 219-225. doi:10.1037/ort0000005

Elbert, T., Schauer, M., Schauer, E., Huschka, B., Hirth, M., \& Neuner, F. (2009). Trauma-related impairment in children-A survey in Sri Lankan provinces affected by armed conflict. Child Abuse \& Neglect, 33, 238-246. doi:10.1016/j.chiabu.2008.02.008

*Espié, E., Ouss, L., Gaboulaud, V., Candilis, D., Ahmed, K., Cohuet, S., ... Moro, M.-R. (2011). Against the odds: Psychomotor development of children under 2 years in a Sudanese orphanage. Journal of Tropical Pediatrics, 57, 412-417. doi:10.1093/tropej/fmq117

Felitti, V. J., Anda, R. F., Nordenberg, D., Williamson, D. F., Spitz, A. M., Edwards, V., ... Marks, J. S. (1998). Relationship of childhood abuse and household dysfunction to many of the leading causes of death in adults. The Adverse Childhood Experiences (ACE) Study. American Journal of Preventive Medicine, 14, 245-258. doi:10.1016/S0749-3797(98)00017-8

Field, T. (2002). Violence and touch deprivation in adolescents. Adolescents, 37, 735-749.

Frank, D. A., Klass, P. E., Earls, F., \& Eisenberg, L. (1996). Infants and young children in orphanages: One view from pediatrics and child psychiatry. Pediatrics, 97, 569-578.

Frankenburg, W. K., \& Dodds, J. B. (1990). Denver II. Denver, CO: Denver Developmental Materials.

*Gavrin, J. B., \& Sacks, L. S. (1963). Growth potential of preschoolaged children in institutional care: A positive approach to a negative condition. American Journal of Orthopsychiatry, 33, 399-408.

Gershoff, E. T. (2002). Corporal punishment by parents and associated child behaviors and experiences: A meta-analytic and theoretical review. Psychological Bulletin, 128, 539-579. doi:10.1037//00332909.128.4.539

Groza, V. K., McCreery Bunkers, K., \& Gamer, G. N. (2011). VII. Ideal components and current characteristics of alternative care options for children outside of parental care in low-resource countries. Monographs of the Society for Research in Child Development, 76, 163-189. doi:10.1111/j.1540-5834.2011. 00632.x 
*Hakimi-Manesh, Y., Mojdehi, H., \& Tashakkori, A. (1984). Short communication: Effects of environmental enrichment on the mental and psychomotor development of orphanage children. Journal of Child Psychology and Psychiatry, 25, 643-650.

Hecker, T., Hermenau, K., Isele, D., \& Elbert, T. (2014). Corporal punishment and children's externalizing problems: A cross-sectional study of Tanzanian primary school students. Child Abuse \& Neglect, 38, 884-892. doi:10.1016/j.chiabu. 2013.11.007

Hecker, T., Hermenau, K., Salmen, C., Teicher, M. H., \& Elbert, T. (2016). Child abuse relates to internalizing problems and cognitive functioning. Manuscript Submitted for Publication.

Hecker, T., Radtke, K., Hermenau, K., Papassotiropoulos, A., \& Elbert, T. (2016). Associations between child abuse, mental health and epigenetic modifications in the proopiomelanocortin gene (POMC): A study with children in Tanzania. Development \& Psychopathology. Advance online publication. doi:10.1017/ S0954579415001248

Hermenau, K., Eggert, I., Landolt, M. A., \& Hecker, T. (2015). Neglect and perceived stigmatization impact psychological distress of orphans in Tanzania. European Journal of Psychotraumatology, 6, 28617. doi:10.3402/ejpt.v6.28617

Hermenau, K., Hecker, T., Elbert, T., \& Ruf-Leuschner, M. (2014). Maltreatment and mental health in institutional care-comparing early - and late-institutionalized children in Tanzania. Infant Mental Health Journal, 35, 102-110. doi:10.1002/imhj.21440

*Hermenau, K., Hecker, T., Ruf, M., Schauer, E., Elbert, T., \& Schauer, M. (2011). Childhood adversity, mental ill-health and aggressive behavior in an African orphanage: Changes in response to trauma-focused therapy and the implementation of a new instructional system. Child and Adolescent Psychiatry and Mental Health, 5, 29. doi:10.1186/1753-2000-5-29

*Hermenau, K., Kaltenbach, E., Mkinga, G., \& Hecker, T. (2015). Improving care quality and preventing maltreatment in institutional care - A feasibility study with caregivers. Frontiers in Psychology, 6, 937. doi:10.3389/fpsyg.2015.00937

Hungerford, A., \& Cox, M. J. (2006). Family factors in child care research. Evaluation Review, 30, 631-655. doi:10.1177/ 0193841 X06291532

*Hunt, J. M., Mohandessi, K., Ghodssi, M., \& Akiyama, M. (1976). The psychological development of orphanage-reared infants: Interventions with outcomes (Tehran). Genetic Psychology Monographs, 94, 177-226.

Johnson, D. E., Dovbnya, S. V., Morozova, T. U., Richards, M. A., \& Bogdanova, J. G. (2014). From institutional care to family support: Development of an effective early intervention network in the Nizhny Novgorod region, Russian Federation, to support family care for children at risk for institutionalization. Infant Mental Health Journal, 35, 172-184. doi:10.1002/ imhj. 21433

Johnson, D. E., Guthrie, D., Smyke, A. T., Koga, S. F., Fox, N. A., Zeanah, C. H., \& Nelson, C. A. (2010). Growth and associations between auxology, caregiving environment, and cognition in socially deprived Romanian children randomized to foster vs ongoing institutional care. Archives of Pediatrics and Adolescent Medicine, 164, 507-519.
Johnson, R., Browne, K., \& Hamilton-Giachritsis, C. (2006). Young children in institutional care at risk of harm. Trauma, Violence, \& Abuse, 7, 34-60. doi:10.1177/1524838005283696

*Kim, T. I., Shin, Y. H., \& White-Traut, R. C. (2003). Multisensory intervention improves physical growth and illness rates in Korean orphaned newborn infants. Research in Nursing \& Health, 26, 424-433. doi:10.1002/nur.10105

Lakens, D. (2013a). Calculating and reporting effect sizes to facilitate cumulative science: A practical primer for t-tests and ANOVAs. Frontiers in Psychology, 4, 863. doi:10.3389/fpsyg.2013.00863

Lakens, D. (2013b). Data Sheet 1 [XLSX document]. Retrieved from http://journal.frontiersin.org/Journal/10.3389/fpsyg.2013.00863/ abstract

*Lecannelier, F., Silva, J. R., Hoffmann, M., Melo, R., \& Morales, R. (2014). Effects of an intervention to promote socioemotional development in terms of attachment aecurity: A study in early institutionalization in Chile. Infant Mental Health Journal, 35, 151-159. doi:10.1002/imhj.21436

Li, X., Naar-King, S., Barnett, D., Stanton, B., Fang, X., Thurston, C., \& Turston, C. (2008). A developmental psychopathology framework of the psychosocial needs of children orphaned by HIV. Journal of the Association of Nurses in Aids Care, 19, 147-157. doi:10.1016/j.jana.2007.08.004

Maundeni, T., \& Malinga-Musamba, T. (2013). The role of informal caregivers in the well-being of orphans in Botswana: A literature review. Child \& Family Social Work, 18, 107-116. doi:10.1111/j. 1365-2206.2011.00820.x

McCall, R. B. (2013). The consequences of early institutionalization: Can institutions be improved?-Should they? Child and Adolescent Mental Health, 18, 193-201. doi:10.1111/camh.12025

McCall, R. B., \& Groark, C. J. (2015). Research on institutionalized children: Implications for international child welfare practitioners and policymakers. International Perspectives in Psychology: Research, Practice, Consultation, 4, 142-159. doi:10.1037/ ipp0000033

*McCall, R. B., Groark, C. J., Fish, L. E., Harkins, D., Serrano, G., Gordan, K., ... Gordon, K. (2010). A socioemotional intervention in a Latin American orphanage. Infant Mental Health Journal, 31, 521-542. doi:10.1002/imhj.20270

McCall, R. B., Groark, C. J., \& Rygaard, N. P. (2014). Global research, practice, and policy issues on the care of infants and young children at risk: The articles in context. Infant Mental Health Journal, 35, 87-93. doi:10.1002/imhj.21441

McGowan, P. O., Sasaki, A., D’Alessio, A. C., Dymov, S., Labonté, B., Szyf, M., ... Meaney, M. J. (2009). Epigenetic regulation of the glucocorticoid receptor in human brain associates with childhood abuse. Nature Neuroscience, 12, 342-348. doi:10.1038/nn.2270

Merz, E. C., McCall, R. B., \& Wright, A. J. (2013). Attention and language as mediators of academic outcomes following early psychosocial deprivation. International Journal of Behavioral Development, 37, 451-459. doi:10.1177/0165025413490867

National Institute of Child Health and Human Development Early Child Care Research Network. (2002). Child Care Structure $\rightarrow$ Process $\rightarrow$ Outcome: Direct and indirect effects of caregiving quality on young children's development. Psychological Science, 13, 199-306. doi:10.1111/1467-9280.00438 
Neimetz, C. (2010). Navigating family roles within an institutional framework: An exploratory study in one private Chinese orphanage. Journal of Child and Family Studies, 20, 585-595. doi:10. 1007/s10826-010-9431-2

Nelson, C. a., Zeanah, C. H., Fox, N. a., Marshall, P. J., Smyke, A. T., $\&$ Guthrie, D. (2007). Cognitive recovery in socially deprived young children: The Bucharest Early Intervention Project. Science, 318, 1937-1940. doi:10.1126/science.1143921

Oliveira, P. S., Soares, I., Martins, C., Silva, J. R., Marques, S., Baptista, J., \& Lyons-Ruth, K. (2012). Indiscriminate behavior observed in the strange situation among institutionalized toddlers: Relations to caregiver report and to early family risk. Infant Mental Health Journal, 33, 187-196. doi:10.1002/imhj.20336

Pinheiro, P. S. (2006). World report on violence against children. An United Nations Children's Fund's report. Retrieved from http://www.unicef.org/violencestudy/reports/SG_violencestudy_ en.pdf

Rather, Y. H., \& Margoob, M. H. (2006). The children living in orphanages in Kashmir: An exploration of their nurture, nature and needs. JK-Practitioner, 13, 49-52.

*Rheingold, H. (1956). The modification of social responsiveness in instituional babies. Monographs of the Society for Research in Child Development, 21, 1-48.

Ruf, M., \& Schauer, M. (2012). Facing childhood trauma: Narrative exposure therapy within a cascade model of care. In J. Murray (Ed.), Exposure therapy: New developments (pp. 229-261). New York, NY: Nova Science.

Rygaard, N. P. (2010). Designing the Fair Start Project-A free e-learning and organizational development program for orphanages and foster families in quality caregivning. Clinical Neuropsychology, 7, 181-187. Retrieved from http://www.clinicalneuropsychia try.org/pdf/02_rygaard.pdf

*Saltz, R. (1973). Effects of part-time "mothering" on IQ and SQ of young institutionalized children. Child Development, 44, 166. doi: $10.2307 / 1127695$

*Sayegh, Y., \& Dennis, W. (1965). The effect of supplementary experiences upon the behavioral development of infants in institutions. Child Development, 36, 81-90. doi:10.2307/1126782

*Smyke, A. T., Dumitrescu, A., \& Zeanah, C. H. (2002). Attachment disturbances in young children. I: The continuum of caretaking casualty. American Academy of Child and Adolescent Psychiatry, 41, 972-982.

*Sparling, J., Dragomir, C., Ramey, S. L., \& Florescu, L. (2005). An educational intervention improves developmental progress of young children in a Romanian orphanage. Infant Mental Health Journal, 26, 127-142. doi:10.1002/imhj.20040

Stoltenborgh, M., Bakermans-Kranenburg, M. J., Alink, L. R. a., \& van Ijzendoorn, M. H. (2012). The universality of childhood emotional abuse: A meta-analysis of worldwide prevalence. Journal of Aggression, Maltreatment \& Trauma, 21, 870-890. doi:10.1080/ 10926771.2012.708014

Stoltenborgh, M., Bakermans-Kranenburg, M. J., van Ijzendoorn, M. H., \& Alink, L. R. A. (2013). Cultural-geographical differences in the occurrence of child physical abuse? A meta-analysis of global prevalence. International Journal of Psychology, 48, 81-94. doi: 10.1080/00207594.2012.697165
Straus, M. A. (2010). Prevalence, societal causes, and trends in corporal punishment by parents in world perspective. Law and Contemporary Problems, 31, 1-30. Retrieved from http:// scholarship.law.duke.edu/lcp/vol73/iss $2 / 2$

*Taneja, V., Sriram, S., Beri, R., Sreenivas, V., Aggarwal, R., Kaur, R., \& Puliyel, J. (2002). "Not by bread alone": Impact of a structured 90-minute play session on development of children in an orphanage. Child: Care, Health \& Development, 28, 95-100.

*The St. Petersburg-USA Orphanage Research Team. (2008). The effects of early social-emotional and relatioship experience on the development of young orphanage children. Monographs of the Society for Research in Child Development, 73, vii-295. doi:10. 1111/j.1540-5834.2008.00483.x.

United Nations Children's Emergency Fund. (2014). The state of the world's children 2014 in numbers, every child counts: Revealing disparities, advancing children's rights. Retrieved from http:// www.unicef.org/publications/index_71829.html

Van Ijzendoorn, M. H., Juffer, F., \& Klein Poelhuis, C. W. (2005). Adoption and cognitive development: A meta-analytic comparison of adopted and nonadopted children's IQ and school performance. Psychological Bulletin, 131, 301-316. doi:10.1037/0033-2909. 131.2.301

Van Ijzendoorn, M. H., Luijk, M. P. C. M., \& Juffer, F. (2008). IQ of children growing up in children's homes. A meta-analysis in IQ delays in orphanages. Merill-Palmer Quarterly, 54, 341-366.

Vashchenko, M., Easterbrooks, M. A., \& Miller, L. C. (2010). Becoming their mother: Knowledge, attitudes, and practices of orphanage personnel in Ukraine. Infant Mental Health Journal, 31, 570-590. doi:10.1002/imhj.20272

Walakira, E. J., Ochen, E. A., Bukuluki, P., \& Alllan, S. (2014). Residential care for abandoned children and their integration into a family-based setting in Uganda: Lessons for policy and programming. Infant Mental Health Journal, 35, 144-150. doi:10.1002/ imhj. 21432

*Wolff, P. H., Dawit, Y., \& Zere, B. (1995). The Solomuna orhanage: A historical survey. Social Sciences \& Medicine, 40, 1133-1139. doi:10.1016/0277-9536(94)00168-S

Wolff, P. H., \& Fesseha, G. (1998). The orphans of Eritrea: Are orphanages part of the problem or part of the solution? The American Journal of Psychiatry, 155, 1319-1324. Retrieved from http:// www.ncbi.nlm.nih.gov/pubmed/9766761

World Bank. (2014). Country and lending groups. Retrieved from http://data.worldbank.org/about/country-and-lending-groups

*Wright, A. C., Lamsal, D., Ksetree, M., Sharma, A., \& Jaffe, K. (2014). From maid to mother: Transforming facilities, staff training, and caregiver dignity in an institutional facility for young children in Nepal. Infant Mental Health Journal, 35, 132-143. doi:10.1002/imhj.21429

\section{Author Biographies}

Katharin Hermenau, $\mathrm{PhD}$, is a postdoctoral research fellow at the Department of Psychology, University of Konstanz, Germany. Her work focuses on consequences and prevention of child maltreatment in families, foster families, and institutional care. She has published several peer-reviewed articles on organized and family violence, 
orphaned, and institutionalized children. One focus of her work is the prevention of child maltreatment in countries with limited resources. She also works at the Center of Excellency for Psychotraumatology at the University of Konstanz as a researcher and trauma therapist. As a board member of vivo international, she facilitates the implementation of evidence-based intervention in countries with limited access to mental health care.

Katharina Goessmann, BSc, attained her bachelor's degree in psychology at the University of Konstanz, Germany. For her master's degree, she is currently studying at the University of Konstanz, Germany and the University of Burgundy in Dijon, France, with a special focus on developmental psychology. Her main research interest is the prevention of violence and maltreatment in families and school settings.

Niels Peter Rygaard, MA, is a clinical child psychologist and consultant in private practice for Danish special needs institutions, schools, foster families, social workers, and clinicians. He is the author of Severe Attachment Disorder and several studies and articles on the topics of adoption, attachment-based treatment, and development of quality care for children at risk. He is a teacher and consultant for Danish state organizations in the fields of adoption and intervention programs for mothers at risk and programs to increase resilience in children. From 2008-2010, he developed together with an international research based network the program Fairstart and founded the NGO FairstartGlobal.

Markus A. Landolt, $\mathrm{PhD}$, is an extraordinary professor at the Institute of Psychology, University of Zurich and the head of pediatric psychology at the University Children's Hospital in Zurich, Switzerland. Trained in family therapy and cognitive-behavioral therapy, he is specialized in clinical work and research with medically traumatized children and their parents. He has published numerous articles on posttraumatic stress in pediatric patients including also very young children. In recent years, he has conducted several psychological intervention studies in traumatized children. He is the author of the first German monography on child psychotraumatology and editor of a handbook on child trauma therapy. $\mathrm{He}$ was the recipient of the Falk-von-Reichbach Award from the German speaking Society for Traumatic Stress Studies in 2005 and was awarded Fellow of the American Psychological Association in 2010. He is also a member of the editorial board for the European Journal of Psychotraumatology.

Tobias Hecker, $\mathrm{PhD}$, is a postdoctoral research fellow at the Institute of Psychology, University of Zurich, Switzerland. Previously, he has worked as postdoctoral research fellow at the Department of Psychology and the Center of Excellency for Psychotraumatology at the University of Konstanz, Germany. His research focuses on consequences and prevention of organized, community, and family violence. He has published several articles on organized, community and family violence, posttraumatic stress, and child maltreatment and served as peer reviewer for numerous scientific journals. He is also a member of the editorial board of BMC Psychiatry. He has worked extensively in African countries, for example, in Tanzania, Uganda, and DR Congo. As an active member of vivo international, He facilitates the implementation of evidence-based intervention in countries with limited access to mental health care. 